T he majority of patients with inflammatory bowel disease (IBD) are affected during their peak reproductive years. ${ }^{1}$ While initial concerns focus on attaining a durable remission and avoiding the side effects of medications, once in remission the focus often shifts to the effect of disease and the medications used to treat it on fertility and the ability to conceive a healthy child. This paper summarises the existing literature on the effects of ulcerative colitis (UC) and Crohn's disease $(\mathrm{CD})$ and the medications used to treat it on fertility and pregnancy outcomes.

\title{
GENETICS AND INHERITANCE
}

Patients are naturally concerned about passing their disease on to their offspring. Unfortunately, family history is the strongest predictor for developing IBD. If one parent is affected, the risks of the offspring developing IBD are $2-13$ times higher than in the general population. ${ }^{2}{ }^{3}$ One study estimated that the risks of IBD in first degree relatives of probands with UC and CD were $1.6 \%$ and $5.2 \%$, respectively, values that were even higher in the Jewish population. ${ }^{4}$ If both parents have IBD, the risk of their offspring developing IBD over their lifetime was estimated to be $36 \%{ }^{5}$

Several studies suggest that breastfeeding may be protective against the development of IBD in the infant. In a meta-analysis of 17 studies, the eight highest quality studies showed a pooled odds ratio of $0.45(0.26,0.79)$ for $\mathrm{CD}$ and $0.56(0.38,0.81)$ for UC. ${ }^{6}$ However, these were not mothers who had IBD themselves.

\section{FERTILITY}

Infertility is defined as the diminished ability or the inability to conceive and have offspring. It is also defined in specific terms as failure to conceive after a year of regular intercourse without contraception. In general, women with CD appear to have similar fertility rates to the general population. Older referral centre studies estimated infertility rates of $32-42 \%$ in women with $\mathrm{CD}^{78}$; however, community based and population based studies suggest infertility rates (5-14\%) similar to the general population. ${ }^{9}{ }^{10}$ Surgery for CD may decrease fertility compared with medical therapy alone. ${ }^{10}$

Women with UC have fertility rates similar to the general population prior to surgery. ${ }^{9-11} \mathrm{~A}$ study by Olsen and colleagues ${ }^{12}$ of 290 women with UC versus 661 non-IBD controls found that women with UC had fecundability ratios (FR) (the ability to conceive per menstrual cycle with unprotected intercourse) equal to the general population ( $F R=1.01)$. However, after surgery for an ileal pouch anal anastomosis (IPAA), FR dropped to $0.20(\mathrm{p}<0.001)$ (see fig 1$)$. This finding was confirmed by Johnson and colleagues ${ }^{13}$ who showed a $38.6 \%$ infertility rate in UC patients after IPAA versus $13.3 \%$ in UC patients managed non-operatively $(\mathrm{p}<0.001)$. The reduction in fertility may be due to surgery in the pelvis and the consequent adhesions and damage to the reproductive organs. Patients who undergo a proctocolectomy with ileostomy also experience a reduction in fertility, ${ }^{14}$ as do patients with familial adenomatous polyposis who undergo IPAA. ${ }^{15}$

The risk of infertility after IPAA should be discussed with the patient prior to surgery as one of the potential risks of the operation. It is unclear if techniques such as laparoscopic IPAA or a subtotal colectomy with rectal stump and ileostomy during the childbearing years and then creating an IPAA later in life are helpful in reducing infertility rates. The drawbacks of the latter procedure include rare ileostomy complications during pregnancy such as obstruction and stoma related problems, ${ }^{16}$ technical difficulties in creating a functioning pouch several years after the initial surgery, and the patient's reluctance to have a long term ostomy.

In men with IBD, the true rate of fertility is not known and is a difficult end point to measure.

Correspondence to: Dr U Mahadevan, Department of Medicine, University of California San Francisco, Center for Colitis and CD, 2330 Post Street \#610, San Francisco, CA 94115 USA; uma.mahadevan@ucsf.edu
A case control study of 42 married men with CD versus 42 married healthy controls noted that prior to diagnosis, both groups had similar numbers of children ( $1.2 v 1.5)$; however, after disease diagnosis, there was a statistically lower number of children born to men with CD than to their age matched controls $(0.4 v 0.8 ; \mathrm{p}<0.05) .{ }^{17}$ This finding was independent of site of disease and medical therapy with sulphasalazine or steroids. In a survey of 106 men with CD, 62 men with UC, and 140 controls, the mean number of pregnancies in the CD patients was significantly lower 


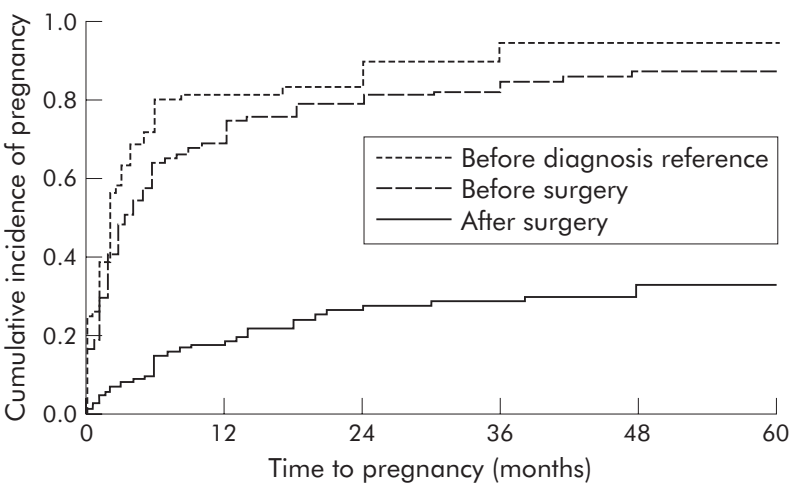

Figure 1 Fecundability ratio in patients with ulcerative colitis before and after diagnosis, and after ileal pouch anal anastomosis compared with healthy controls. Reprinted from Olsen and colleagues ${ }^{12}$ with permission from the American Gastroenterological Association.

than the number for controls $(\mathrm{p}<0.02) .{ }^{18}$ However, in UC patients, the number was not statistically different. Fecundability (the probability of pregnancy per menstrual cycle with unprotected intercourse) was similar between IBD patients and controls, suggesting a high rate of voluntary infertility in men with CD. Surgery, particularly in the pelvis, can also lead to issues with fertility although this is not well studied in men. Men who undergo IPAA for UC may experience retrograde ejaculation and erectile dysfunction, ${ }^{19}$ but overall male sexual function is reported to improve after IPAA. $^{20}$

Semen quality is a surrogate marker for fertility and is measured by volume, concentration, motility, progression, total motile count, and normal oval forms. ${ }^{21}$ These factors are all important in determining fertility although no single measure is diagnostic of infertility. A small case series noted a $46 \%$ rate of oligospermia and reduced sperm motility in men with $\mathrm{CD}^{22}$ Abnormal semen quality in $\mathrm{CD}$ has been associated with disease activity, ${ }^{23}$ poor nutritional status, ${ }^{22}$ and zinc deficiency. ${ }^{24}$ These data suggest that being in remission-with inactive disease and good nutritional status-is important for sperm health and, by extrapolation, conception. Therefore, continuing medications to maintain in remission during the conception period is of benefit, as long as the medications themselves do not affect fertility or pregnancy outcome.

\section{PREGNANCY OUTCOMES}

The perinatal outcomes of the children of fathers with UC and $C D$ have not been shown to differ from that of the general population. ${ }^{25}$ However, in women, population based studies have shown an increased risk of preterm birth, low birth weight, and small for gestational age infants. ${ }^{26-28}$ Caesarean sections are also more common in women with IBD. ${ }^{27} \mathrm{~A}$ population based cohort study by Dominitz and colleagues $^{29}$ used the computerised birth records of Washington State to compare pregnancy outcomes in 107

- Overall, patients with IBD have similar fertility rates to the general population. However, surgery, disease activity, and certain medications may impact on fertility. If a couple is having difficulty conceiving despite a six month trial, referral should be made to a fertility specialist to determine if a correctable cause can be found and whether alternative methods of conception can be offered.
UC and 155 CD patients to 1308 controls. Women with CD had significantly higher rates of preterm delivery, low birth weight, and small for gestational age infants compared with controls. In contrast, women with UC had similar rates to controls but a significantly higher rate of congenital malformations $(7.9 \% \vee 1.7 \%)$. The study did not account for medication use and the results have not been replicated in other studies. The Hungarian Case Control Surveillance of congenital anomalies was queried from 1980 to $1996 .{ }^{30}$ The odds ratio of congenital anomalies in UC patients versus controls was $1.3(0.9,1.8)$, adjusted for parity, age, and medication use.

We recently completed a population representative study of women with IBD using the Northern California Kaiser population. ${ }^{31}$ Women with IBD $(\mathrm{n}=461)$, compared with controls $(n=495)$, were found to have higher rates of any adverse outcome, adverse conception outcomes (spontaneous or therapeutic abortion), adverse pregnancy outcomes (preterm birth, low birth weight, intrauterine growth retardation, small for gestational age infants, congenital anomalies, APGAR scores, and stillbirth), and complications of labour. Newborn measures (NICU admission, hyperbilirubinaemia, seizures, mortality) were not different between the groups. Predictors of poor outcome in this study were having IBD, either UC or CD, and having had surgery for IBD. Unlike other studies, disease activity and medication use were not predictors of adverse outcome. In prior studies, disease activity at conception was associated with a higher rate of fetal $\operatorname{loss}^{32}$ and preterm birth ${ }^{33}$; disease activity during pregnancy was associated with low birth weight and preterm birth. ${ }^{34}$ Other potential predictors of an adverse outcome include ileal $\mathrm{CD}^{36}$ and previous bowel resection. ${ }^{3136}$ The difference between our study and others on the effect of disease activity on pregnancy outcome may possibly be explained by the fact that we had a larger cohort and a population representative sample as opposed to a referral centre series.

\section{EFFECT OF PREGNANCY ON IBD}

In general, women with IBD are as likely to flare during pregnancy as they are when not pregnant. Nielsen et al reported an exacerbation rate of $34 \%$ per year during pregnancy and $32 \%$ per year when not pregnant in women with UC. ${ }^{33}$ Pregnant women with CD also had similar rates of disease exacerbation. ${ }^{37}$

\section{LABOUR AND DELIVERY}

There is an increased rate of Caesarean sections in women with IBD. ${ }^{27}$ In general, the decision to have a Caesarean section should be made on purely obstetric grounds. The two exceptions are active perianal disease and the presence of an ileoanal pouch. If a patient has inactive perianal disease or no history of perianal disease, they are not at increased risk for perianal disease after a vaginal delivery. ${ }^{38}$ However, if they have active perianal disease they can risk aggravating their injury with a vaginal delivery. One report noted an increased

- Women with IBD clearly have an increased risk of an adverse event during pregnancy. They should be followed by a high risk obstetrician in addition to their general obstetrician and gastroenterologist to monitor for poor fetal development and to keep their IBD under good control. 
incidence of perianal disease following episiotomy, ${ }^{39}$ but this has not been replicated in other studies.

Patients who have an IPAA can have a normal vaginal delivery without fears of damaging the pouch. ${ }^{40}$ However, the concern with vaginal delivery is for damage to the anal sphincter. While pouch function may deteriorate during pregnancy, after pregnancy it reverts to the pre-pregnancy state. $^{40}$ However, damage to the anal sphincter may be compounded by aging and the effects on the pouch will not be seen for several years. The patient, their obstetrician, and their surgeon should discuss the theoretical risk to long term pouch function prior to making a decision on mode of delivery.

\section{MEDICATIONS}

The use of medications during the conception period and pregnancy is a cause of great concern for patients and the physicians caring for them. Overall, the majority of medications used for the treatment of IBD are not associated with significant adverse effects, and maintaining the health of the mother remains a priority in the management of these patients. The United States Food and Drug Administration (FDA) classification of drugs offers a guide to the use of medications during pregnancy. The FDA categories are listed in table 1 and are noted for each drug discussed. Table 2 summarises the safety of IBD medications for pregnancy and breastfeeding.

\section{Medications during conception and pregnancy in women \\ Aminosalicylates}

All aminosalicylates (sulfasalazine, mesalamine, balsalazide) are pregnancy category B except olsalazine, which is category C. Initial case reports suggested sulfasalazine associated teratogenicity with evidence of cardiovascular, genitourinary, and neurological defects. ${ }^{41-43}$ However, a larger series of 181 pregnant women ${ }^{44}$ and a population based study using the Hungarian Case Control Surveillance of Congenital Abnormalities database ${ }^{45}$ did not find a significant increase in the prevalence of congenital abnormalities. Given the concern over potential antifolate effects of the drug, it is recommended that women take at least $2 \mathrm{mg}$ of folic acid daily in the prenatal period and throughout pregnancy. Breastfeeding is also considered compatible with sulfasalazine. Unlike other sulfonamides, bilirubin displacement, and therefore kernicterus, does not occur in the infant. ${ }^{46}$

Case series, ${ }^{47-49}$ a prospective controlled trial of 165 women exposed to mesalamine compared with matched controls with no exposure, ${ }^{50}$ and a population based cohort study from
Denmark $^{51}$ have not demonstrated an increased teratogenic risk with mesalamine. While 5-ASAs are compatible with breastfeeding, there is a rare association with diarrhoea in the infant. ${ }^{52}$ Should this occur, breastfeeding should be discontinued.

\section{Antibiotics}

Data suggest there is not a significantly increased risk of adverse events with the short term use of metronidazole and the quinolones in pregnancy. However, given the limited evidence of benefit of these agents in IBD, and the extended duration of use in the treatment of luminal CD and UC, long term use during pregnancy for this indication should be avoided. Short courses for the treatment of pouchitis and perianal disease are low risk.

Metronidazole is pregnancy category B. Multiple studies have suggested that prenatal use of metronidazole is not associated with birth defects, including two meta-analyses, ${ }^{53}{ }^{54}$ two retrospective cohort studies, ${ }^{55}$ and a prospective controlled study of 228 women exposed to metronidazole during pregnancy. ${ }^{57}$ A population based case control study found that overall teratogenic risk was low, but infants of women exposed to metronidazole in the second to third months of pregnancy had higher rates of cleft lip with or without cleft palate. ${ }^{58}$ This increase was slight and not felt to be clinically significant. Potential toxicity exists for long term use of metronidazole while breastfeeding and therefore it is considered not compatible.

Quinolones (for example, ciprofloxacin, levofloxacin, norfloxacin) are FDA category $\mathrm{C}$ and have a high affinity for bone tissue and cartilage and may cause arthropathies in children. $^{59}$ A prospective controlled study of 200 women $^{60}$ and a population based cohort study of 57 women exposed to quinolones $^{61}$ did not find an increased risk of congenital malformations. Overall, the risk is thought to be minimal, but given safer alternatives, the drug should be avoided in the first trimester. Data on breastfeeding are limited but it is probably compatible with use. ${ }^{62}$

Rifaximin is pregnancy category C. This is a new agent and little information exists on safety in pregnancy. Rifaximin has not been found to effect fertility or pregnancy outcome in rats $^{63}$ but can cause teratogenic complications in rats and rabbits. ${ }^{64}$ Safety in breastfeeding is unknown.

An alternative antibiotic for pouchitis is amoxicillin/clavulanic acid, pregnancy category B. A population based case control study $y^{65}$ and a prospective controlled study ${ }^{66}$ did not show evidence of increased teratogenic risk and it is compatible with breastfeeding.

\begin{tabular}{|c|c|}
\hline $\begin{array}{l}\text { FDA } \\
\text { category }\end{array}$ & Definition \\
\hline A & $\begin{array}{l}\text { Controlled studies in animals and women have shown no risk in the first trimester, and possible fetal } \\
\text { harm is remote. }\end{array}$ \\
\hline B & $\begin{array}{l}\text { Either animal studies have not demonstrated a fetal risk but there are no controlled studies in } \\
\text { pregnant women, or animal studies have shown an adverse effect that was not confirmed in } \\
\text { controlled studies in women in the first trimester. }\end{array}$ \\
\hline C & $\begin{array}{l}\text { No controlled studies in humans have been performed, and animal studies have shown adverse } \\
\text { events, or studies in humans and animals not available; give if potential benefit outweighs the risk. }\end{array}$ \\
\hline$D$ & $\begin{array}{l}\text { Positive evidence of fetal risk is available but the benefits may outweigh the risk if life threatening or } \\
\text { serious disease. }\end{array}$ \\
\hline $\mathrm{x}$ & Studies in animals or humans show fetal abnormalities; drug contraindicated. \\
\hline
\end{tabular}


Table 2 Medications used in the treatment of inflammatory bowel disease

\begin{tabular}{|c|c|c|c|}
\hline Drug & $\begin{array}{l}\text { FDA } \\
\text { category }\end{array}$ & Recommendations for pregnancy & Breastfeeding $^{62}$ \\
\hline Adalimumab & B & Limited human data: low risk & $\begin{array}{l}\text { No human data: probably } \\
\text { compatible }\end{array}$ \\
\hline Alendronate & C & $\begin{array}{l}\text { Limited human data: animal data } \\
\text { suggest risk. }\end{array}$ & $\begin{array}{l}\text { No human data: probably } \\
\text { compatible }\end{array}$ \\
\hline $\begin{array}{l}\text { Azathioprine/ } \\
\text { 6- mercaptopurine }\end{array}$ & D & $\begin{array}{l}\text { Data in IBD, transplant literature } \\
\text { suggest low risk }\end{array}$ & No human data: potential toxicity \\
\hline Balsalazide & B & Low risk & $\begin{array}{l}\text { No human data: potential } \\
\text { diarrhoea }\end{array}$ \\
\hline Budesonide & C & $\begin{array}{l}\text { Data with inhaled drug low risk. No } \\
\text { human data for oral drug }\end{array}$ & No human data \\
\hline Ciprofloxacin & C & Avoid: potential toxicity to cartilage & $\begin{array}{l}\text { Limited human data: probably } \\
\text { compatible }\end{array}$ \\
\hline Corticosteroids & C & $\begin{array}{l}\text { Low risk: possible small risk of cleft } \\
\text { palate, adrenal insufficiency, } \\
\text { premature rupture of membranes }\end{array}$ & Compatible \\
\hline Ciclosporin & C & Low risk & $\begin{array}{l}\text { Limited human data: potential } \\
\text { toxicity }\end{array}$ \\
\hline Fish oil supplements & - & Safe. Possibly beneficial & No human data \\
\hline Infliximab & B & Low risk: limited human data & $\begin{array}{l}\text { Limited human data: probably } \\
\text { compatible }\end{array}$ \\
\hline Mesalamine & B & Low risk & $\begin{array}{l}\text { Limited human data: potential } \\
\text { diarrhoea }\end{array}$ \\
\hline Methotrexate & $\mathrm{x}$ & Contraindicated: teratogenic & Contraindicated \\
\hline Metronidazole & B & $\begin{array}{l}\text { Given limited efficacy in IBD, would } \\
\text { avoid in first trimester }\end{array}$ & $\begin{array}{l}\text { Limited human data: potential } \\
\text { toxicity }\end{array}$ \\
\hline Olsalazine & C & Low risk & $\begin{array}{l}\text { Limited human data: potential } \\
\text { diarrhoea }\end{array}$ \\
\hline Risedronate & C & Limited human data. & Safety unknown \\
\hline Rifaximin & C & Animal teratogen. No human data & Safety unknown \\
\hline Sulfasalazine & $\mathrm{B}$ & Low risk. Give folate $2 \mathrm{mg}$ daily & $\begin{array}{l}\text { Limited human data: potential } \\
\text { diarrhoea }\end{array}$ \\
\hline Tacrolimus & C & Low risk & $\begin{array}{l}\text { Limited human data: potential } \\
\text { toxicity }\end{array}$ \\
\hline Thalidomide & $x$ & Contraindicated: teratogenic & No human data: potential toxicity \\
\hline
\end{tabular}

\section{Corticosteroids}

Corticosteroids, including budesonide, are FDA category C. A case control study of corticosteroid use during the first trimester ${ }^{67}$ and a large case control study ${ }^{68}$ noted an increase risk of oral clefts in the newborn. However, a prospective controlled study of 311 women who received glucocorticosteroids during the first trimester did not note an increased rate of major anomalies and no cases of oral cleft were noted. ${ }^{69} \mathrm{~A}$ meta-analysis reported a summary odds ratio for case control studies examining the risk of oral clefts of 3.35 (95\% confidence interval (CI) 1.97, 5.69) ${ }^{70}$; however, the overall risk of major malformations was low (1.45 (95\% CI $0.80,2.60))$. An increased risk of premature rupture of membranes and adrenal insufficiency in the newborn has been reported in the transplant setting. ${ }^{71}$ Overall, the use of corticosteroids pose a very small risk to the developing infant when used in the first trimester, a risk which is outweighed by the benefit of controlling the mother's IBD. The mother needs to be informed of both the benefits and risks of therapy. Prednisone and prednisolone are compatible with breastfeeding.

There are no data on oral budesonide safety in pregnancy. However, inhaled or intranasal budesonide is not associated with adverse fetal outcomes. ${ }^{72}{ }^{73}$ Safety in lactation is not known.

\section{Bisphosphonates}

The bisphosphonates, alendronate and risedronate, are used for the treatment and prevention of osteoporosis. Many patients with IBD are started on these medications in conjunction with corticosteroids for prevention of bone loss. Alendronate and risedronate are category $\mathrm{C}$ and the safety in breastfeeding is unknown. Both agents should be avoided in pregnancy as animal studies show that alendronate does cross the placenta and store in fetal bone, causing anatomical changes. ${ }^{74}$ The effects to human fetal bone development are unknown. The half life of alendronate is greater than 10 years and it accumulates in bone. The concern in giving this agent to a woman of child bearing potential is that the drug is slowly released from bone and may result in a low level of continuous exposure to the fetus throughout gestation. Risedronate has a reported half life of 20 days but data from an ongoing study by the manufacturer suggests that the half life may be significantly longer. The long term use of bisphosphonates in women of child bearing potential should be done with caution and under the guidance of an endocrinologist.

\section{Immunomodulators}

\section{Methotrexate}

Methotrexate, category $\mathrm{X}$, is clearly teratogenic and should not be used in women considering conception. Methotrexate is a folic acid antagonist and use during the critical period of organogenesis (6-8 weeks post-conception) is associated with multiple congenital anomalies collectively called methotrexate embryopathy or the fetal aminopterin-methotrexate syndrome. ${ }^{62}$ The syndrome is characterised by intrauterine growth retardation, decreased ossification of the calvarium, hypoplastic supraorbital ridges, small low set ears, micrognathia, limb abnormalities, and sometimes mental 
retardation. ${ }^{75}$ Exposure in the second and third trimesters may be associated with fetal toxicity and mortality. ${ }^{62}$ Methotrexate may persist in tissues for long periods and it is suggested that patients wait at least three to six months from discontinuation of the drug prior to attempting conception. Methotrexate is excreted in breast milk and may accumulate in neonatal tissues. It is contraindicated in breastfeeding.

\section{Azathioprine/6-mercaptopurine}

6-Mercaptopurine (6MP) and its pro-drug azathioprine are pregnancy category D. Animal studies have demonstrated teratogenicity with increased frequencies of cleft palate, open eye, and skeletal anomalies seen in mice exposed to azathioprine and cleft palate, and skeletal and urogenital anomalies seen in rats. ${ }^{76}$ Transplacental and transamniotic transmission of azathioprine and its metabolites from the mother to the fetus can occur. ${ }^{77}$ The oral bioavailability of azathioprine $(47 \%)$ and $6 \mathrm{MP}(16 \%)$ is $\mathrm{low}^{76}$ and the immature fetal liver lacks the enzyme inosinate pyrophosphorylase needed to convert azathioprine to $6 \mathrm{MP} .{ }^{78}$ Both features may protect the fetus from toxic drug exposure during the crucial period of organogenesis. The largest evidence on safety comes from transplantation studies where rates of anomalies ranged from $0 \%$ to $11.8 \%$ and no evidence of recurrent patterns of congenital anomalies emerged. ${ }^{76} \mathrm{~A}$ population based cohort study from Denmark compared 11 women exposed to azathioprine or 6-MP to the general population. ${ }^{79}$ The adjusted odds ratio for congenital malformations was 6.7 (1.4-32.4). However, when a single severely ill patient with autoimmune hepatitis and multiple other medications was removed from the cohort, the odds ratio was 3.4 (0.4-27.3). In IBD, multiple case series have not demonstrated an increase in congenital anomalies. ${ }^{80-83}$ Based on the large experience in transplantation patients and the body of evidence in IBD, the drugs are often continued during pregnancy to keep the mother in remission. Given the potential for severe toxicity in the nursing infant, breastfeeding is not recommended. ${ }^{62}$

\section{Ciclosporin and tacrolimus}

Ciclosporin is category C. A meta-analysis of 15 studies of pregnancy outcomes after ciclosporin therapy reported malformations in 410 patients. ${ }^{84}$ The calculated odds ratio of $3.83(0.75-19.6)$ was not statistically significant and the rate of malformations was $4.1 \%$, similar to the general population. In IBD, a case report noted the successful use of ciclosporin in a 27 week pregnant woman with fulminant UC. ${ }^{85}$ In the setting of severe steroid refractory UC, ciclosporin may be a better option than colectomy, which is associated with a high rate of fetal mortality. ${ }^{86}$ Ciclosporin is excreted into breast milk in high concentrations and is contraindicated during breastfeeding.

Tacrolimus is also category C. There is an increased incidence of perinatal hyperkalaemia ${ }^{87}$ and prematurity. ${ }^{88}$ The reported malformation rate is $5.6 \%$ with no persistent anomalies seen. The benefit of tacrolimus over ciclosporin is the lower rates of maternal hypertension and hyperlipidaemia but there is a higher incidence of diabetes in the newborn. ${ }^{89}$ There is a single case report of tacrolimus use in a patient with UC. ${ }^{90}$ This patient was in remission on tacrolimus, was maintained on the drug throughout her pregnancy, and delivered a healthy infant at term. Tacrolimus is contraindicated in breastfeeding because of the high concentrations found in breast milk.

\section{Thalidomide}

Thalidomide, pregnancy category $\mathrm{X}$, has antitumour necrosis factor effects and has been used successfully for the treatment of CD. ${ }^{91}$ However, its teratogenicity has been extensively documented and includes limb defects, central nervous system effects, and abnormalities of the respiratory, cardiovascular, gastrointestinal, and genitourinary system. ${ }^{62}$ Thalidomide is contraindicated during pregnancy and in women of childbearing age who are not using two reliable methods of contraception for one month prior to starting therapy, during therapy, and for one month after stopping therapy. ${ }^{92}$ There are no human data on breastfeeding but it is not advised given the potential toxicity.

\section{Biological therapy Infliximab}

Infliximab is pregnancy category B. A growing body of evidence suggests infliximab is low risk in pregnancy. The two largest studies are from the TREAT registry ${ }^{93}$ and the Infliximab Safety Database ${ }^{94}$ maintained by Centocor (Malvern, Pennsylvania, USA). The TREAT registry is a prospective registry of patients with CD. Of the 5807 patients enrolled, 66 pregnancies were reported, 36 with prior infliximab exposure. Fetal malformations did not occur in any of the pregnancies. Rates of miscarriage ( $11.1 \%$ v $7.1 \%$; $\mathrm{p}=0.53)$ and neonatal complications $(8.3 \% v 7.1 \% ; \mathrm{p}=0.78)$ were not significantly different between infliximab treated and infliximab naïve patients.

The Infliximab Safety Database is a retrospective data collection instrument. Pregnancy outcome data are available for 96 women with direct exposure to infliximab. ${ }^{94}$ The 96 pregnancies resulted in 100 births. The expected versus observed outcomes among women exposed to infliximab were not different from those of the general population (see fig 2). In a series of 10 women with maintenance infliximab use throughout pregnancy, ${ }^{95}$ all pregnancies ended in live births, with no congenital malformations.

Infliximab does cross the placenta. A recent case report ${ }^{96}$ noted high infliximab levels in an infant born to a mother on infliximab therapy every four weeks. The mother breastfed

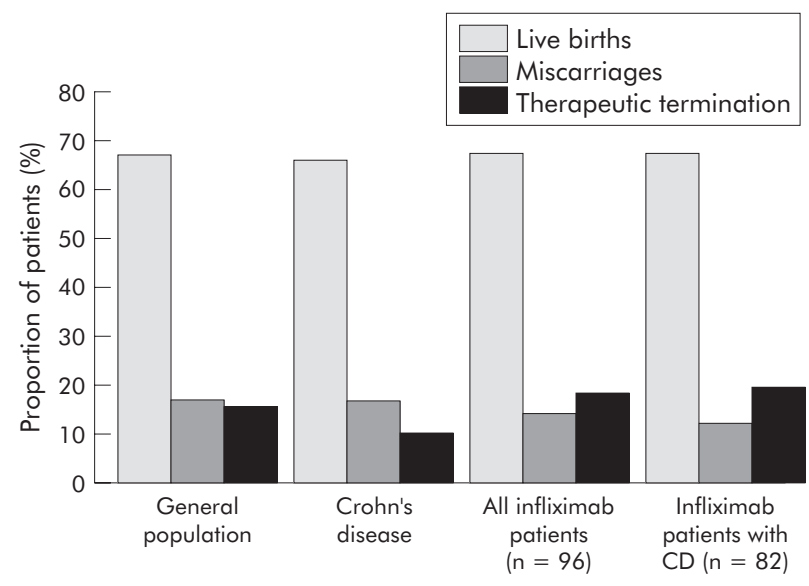

Figure 2 Outcomes of women exposed to infliximab during pregnancy. CD, Crohn's disease. From Katz and colleagues ${ }^{94}$ and Ventura and colleagues (National Center for Health Statistics. Vital Health Stat 2000;21:1-59). 
and continued to receive infliximab but the infant's infliximab level dropped over six months, suggesting placental rather than breast milk transfer. The effect of the high infliximab levels on the infant's developing immune system is not known, although at seven months the infant had normal $\mathrm{T}$ and $\mathrm{B}$ cell development and appropriate response to vaccination.

It is not known whether infliximab is excreted in human milk or absorbed systemically after ingestion. The only available study on infliximab in breast milk found that levels were either not present or were too low to be detected in the single patient studied.${ }^{97}$ Case reports of women who breastfed while on infliximab do not suggest toxicity ${ }^{95} 96$ and it is probably compatible with breastfeeding.

\section{Adalimumab}

Adalimumab, pregnancy category B, has recently demonstrated safety and efficacy for induction of remission in CD. ${ }^{98}$ A case report documented a successful pregnancy in a woman with longstanding CD who began adalimumab one month prior to conception and received a total of 38 doses during her pregnancy. ${ }^{99}$

\section{Fish oil supplements}

Many patients with IBD use fish oil supplements as an adjunct to standard medical therapy. As this is a supplement and not a drug, it is not rated by the FDA. A randomised controlled trial of fish oil supplementation demonstrated prolongation of pregnancy without detrimental effects on the growth of the fetus or on the course of labour. ${ }^{100}$ Fish oil supplementation may also play a role in preventing miscarriage associated with the antiphospholipid antibody syndrome. ${ }^{101}$ In women with IBD who may be at increased risk for preterm birth and miscarriage, fish oil supplementation is not harmful and may be of some benefit.

\section{Medications during conception in men}

Sulfasalazine has been clearly associated with infertility and abnormalities in sperm number, motility, and morphology. ${ }^{102}{ }^{103}$ In a study of 21 patients on sulfasalazine, $86 \%$ had abnormal semen analysis and $72 \%$ had oligospermia. ${ }^{104}$ The effect appears to be reversible: when men were switched from sulfasalazine to mesalamine, semen quality returned to normal. ${ }^{105}{ }^{106}$ An association between sulfasalazine use in the parent and congenital malformations in the progeny has been described. ${ }^{107}$ As the lifespan of sperm is 120 days, men desiring conception should either discontinue sulfasalazine or switch to mesalamine at least four months prior to conception.

The effect of corticosteroid therapy alone on male fertility and congenital anomalies is not known. Burnell and colleagues $^{17}$ did not find an association between steroid therapy and infertility. Corticosteroids are currently used in the treatment of immunological infertility with no evidence of an increase in congenital anomalies. ${ }^{108}$ Based on the limited available data, corticosteroids can be continued during the conception period, keeping in mind that disease activity itself may have a negative impact on fertility and semen quality.

Methotrexate may cause reversible oligospermia in men. ${ }^{109}$ There are no case reports to date of congenital anomalies resulting in the offspring of men on methotrexate. It is recommended that men stop methotrexate for at least four months before attempting conception.
Azathioprine and $6 M P$ do not appear to reduce semen quality in men with IBD versus men with IBD not on azathioprine. ${ }^{110}$ However, both groups did have abnormal semen quality compared with normal controls. One case report described a man with CD who had two successful conceptions prior to initiating 6MP but had secondary infertility after $6 \mathrm{MP} .{ }^{111}$ Semen analysis revealed oligospermia with a concentration of $8000 / \mathrm{ml}$ and $90 \%$ total motility with $20 \%$ forward progressive motility. The couple was able to successfully conceive with intracytoplasmic sperm injection.

Animal data clearly demonstrate dominant lethal mutations in mice receiving azathioprine/6MP with resulting infertility. ${ }^{112} \mathrm{~A}$ recent study in mice gave intraperitoneal injections of $6 \mathrm{MP}$ to male mice for 51 days, ${ }^{113}$ mated them with females after 45 days of treatment, and then examined the products of conception at 13 days of pregnancy. The authors found that treatment with 6MP did not affect sperm morphology or sperm production compared with controls. However, pregnancy rates were inversely related to escalating doses of $6 \mathrm{MP}$. The abortion rate was significantly higher in the 6MP group compared with the control group but the incidence of major congenital malformation was the same. The authors concluded that the high abortion rate coupled with the normal sperm morphology suggested more occult sperm damage at the genetic level. More studies are needed in humans to determine the impact of these agents on male fertility.

Reports in humans are mixed with respect to the occurrence of congenital malformations in the offspring of men on azathioprine/6MP. Two reports support an increased rate of congenital malformations ${ }^{114} 115$ while a larger case series did not find a difference between fathers on 6MP at conception and those who conceived prior to starting the drug. ${ }^{81}$ Recently, a population based study from Denmark showed a trend towards increased congenital malformations in fathers on 6MP with an adjusted odds ratio of 1.8 (95\% CI $0.7-5.0) .{ }^{116}$ In exposed pregnancies, there was a $7.4 \%$ rate of congenital abnormalities versus $4.1 \%$ in controls. All congenital anomalies in the exposed group were in male infants. The use of azathioprine/6MP during the conception period remains controversial. At this time, there is no conclusive data to recommend stopping the medication during the conception period.

Infliximab appears to be low risk. Data in mice treated with an analogous antibody to mouse tumour necrosis factor $\alpha$ (infliximab cross reactivity is limited to only humans and chimpanzees) reported no detrimental effects on male reproduction. ${ }^{117}$ In a study by Katz et al of 10 men who received infliximab near the time of conception, there was no

- The use of IBD medication during conception and pregnancy is generally low risk. For a drug to clearly be associated with congenital anomalies, the same defect must be seen repeatedly, a phenomenon not demonstrated with any IBD medication except methotrexate and thalidomide, both of which are contraindicated. Sulfasalazine and methotrexate are associated with reversible sperm abnormalities in men and should be discontinued 4-6 months prior to conception. The risk of an adverse event must be weighed against the benefit to the health of the parent derived by continuing on their medication. 
increase in congenital anomalies in the progeny. ${ }^{94}$ A study of 10 men on infliximab therapy noted a significant increase in semen volume after infliximab infusion and a trend towards a reduction in sperm motility, or the percentage of sperm that showed flagellar motion. ${ }^{118}$ Sperm concentration remained normal; however, in patients receiving infliximab maintenance therapy, there was a significant decrease in the percentage of normal oval forms after infusion, a phenomenon not observed in infliximab naïve patients. This small study suggests that infliximab may affect sperm morphology as well as sperm motility and that the effect on morphology is more profound with increased exposure to infliximab. It has also been demonstrated in vitro, that tumour necrosis factor $\alpha$ effectively and dose dependently inhibits germ cell apoptosis in human seminiferous tubules. ${ }^{119}$ Furthermore, in rat seminiferous epithelium, this prosurvival effect can be blocked by infliximab. ${ }^{120}$ This suggests that effective antitumour necrosis factor therapy in large enough doses may affect sperm count and thereby reduce fertility. The study of human semen quality on infliximab ${ }^{118}$ did not show a change in sperm concentration with infliximab infusion. Lack of infliximab associated changes in sperm concentration in this study could reflect a dose dependent effect of infliximab on spermatogenesis, lack of an in vivo apoptotic effect of infliximab on spermatogenesis, or an insufficient sample size to define this phenomenon. In summary, infliximab treatment in men may decrease sperm motility and morphology. Whether or not these semen analysis findings translate into impaired fertility has not been formally examined. Therefore, at this time, it is not recommended that men receiving infliximab stop therapy if they are considering conception. The risks of stopping treatment include a flare of the underlying IBD and development of antibodies to infliximab that may preclude future use. If infertility is clinically evident and evaluation of the infertile couple suggests that semen quality is abnormal in the absence of other infertility risk factors, then consideration should be given to stopping infliximab treatment at that time.

\section{SUMMARY}

- The peak incidence of IBD overlaps with the prime reproductive years, making the management of IBD patients desiring conception challenging.

- The offspring of patients with IBD are more likely to have IBD than the general population.

- Women with IBD have similar fertility rates to the general population.

- Surgery, particularly an ileal pouch anal anastomosis, reduces fertility.

- Men with IBD may have lower fertility rates than healthy controls.

- Infertility may be voluntary or related to disease activity, malnutrition, surgery, or medication use.

- Pregnancy outcomes

- Women with IBD have higher rates of low birth weight, small for gestational age infants, and preterm birth.

- Women with IBD should be followed as high risk pregnancies.

- The offspring of men with IBD do not seem to have higher rates of perinatal adverse outcomes.

- Pregnancy and IBD

- Women with IBD have a one third risk of flaring during pregnancy.

- A Caesarean section is recommended for obstetric concerns and for active perianal $\mathrm{CD}$ at the time of delivery.
- Medications during conception and pregnancy

- In women, methotrexate and thalidomide are contraindicated during pregnancy and conception. The majority of other medications used to induce or maintain remission are considered low risk and may be continued after a full discussion with the patient.

- In men, sulfasalazine causes reversible sperm abnormalities and methotrexate is associated with oligospermia. Both agents should be stopped 4-6 months prior to considering conception. Other IBD medications are considered low risk.

\section{REFERENCES}

1 Andres PG, Friedman LS. Epidemiology and the natural course of inflammatory bowel disease. Gastroenterol Clin North Am 1999;28:255-81.

2 Orholm M, Fonager K, Sorensen HT. Risk of ulcerative colitis and Crohn's disease among offspring of patients with chronic inflammatory bowel disease. Am J Gastroenterol 1999;94:3236-8.

3 Orholm M, Munkholm P, Langholz E, et al. Familial occurrence of inflammatory bowel disease. N Engl J Med 1991;324:84-8.

4 Yang $\mathrm{H}, \mathrm{McEl}$ ree $\mathrm{C}$, Roth MP, et al. Familial empirical risks for inflammatory bowel disease: differences between Jews and non-Jews. Gut 1993;34:517-24.

5 Bennett RA, Rubin PH, Present DH. Frequency of inflammatory bowel disease in offspring of couples both presenting with inflammatory bowel disease. Gastroenterology 1991;100:1638-43.

6 Klement E, Reif S. Breastfeeding and risk of inflammatory bowel disease. Am J Clin Nutr 2005;82:486.

7 Fielding JF. Pregnancy and inflammatory bowel disease. Ir J Med Sci 1982;151:194-202.

8 Mayberry JF, Weterman IT. European survey of fertility and pregnancy in women with Crohn's disease: a case control study by European collaborative group. Gut 1986;27:821-5.

9 Baird DD, Narendranathan M, Sandler RS. Increased risk of preterm birth for women with inflammatory bowel disease. Gastroenterology 1990;99:987-94

10 Hudson M, Flett G, Sinclair TS, et al. Fertility and pregnancy in inflammatory bowel disease. Int J Gynaecol Obstet 1997;58:229-37.

11 Willoughby CP, Truelove SC. Ulcerative colitis and pregnancy. Gut 1980;21:469-74

12 Olsen KO, Juul S, Berndtsson I, et al. Ulcerative colitis: female fecundity before diagnosis, during disease, and after surgery compared with a population sample. Gastroenterology 2002;122:15-19.

13 Johnson P, Richard C, Ravid A, et al. Female infertility after ileal pouch-anal anastomosis for ulcerative colitis. Dis Colon Rectum 2004;47:1119-26.

14 Wikland M, Jansson I, Asztely M, et al. Gynaecological problems related to anatomical changes after conventional proctocolectomy and ileostomy. Int J Colorectal Dis 1990;5:49-52.

15 Olsen KO, Juul S, Bulow S, et al. Female fecundity before and after operation for familial adenomatous polyposis. Br J Surg 2003;90:227-31.

16 Van Horn C, Barrett P. Pregnancy, delivery, and postpartum experiences of fifty-four women with ostomies. $J$ Wound Ostomy Continence Nurs 1997;24:151-62.

17 Burnell D, Mayberry J, Calcraft BJ, et al. Male fertility in Crohn's disease. Postgrad Med J 1986;62:269-72.

18 Narendranathan $M$, Sandler RS, Suchindran CM, et al. Male infertility in inflammatory bowel disease. J Clin Gastroenterol 1989;11:403-6.

19 Tiainen J, Matikainen M, Hiltunen KM. lleal J-pouch-anal anastomosis, sexual dysfunction, and fertility. Scand J Gastroenterol 1999;34:185-8.

20 Gorgun ERF, Montague D, Connor J, et al. Male sexual function improves after ileal pouch anal anastomosis. Colorect Dis 2005;7:545-50.

21 WHO laboratory manual for the examination of human semen and semen cervical mucus interaction, 3rd edn., Cambridge: Cambridge University
Press 1992.

22 Farthing MJ, Dawson AM. Impaired semen quality in Crohn's diseasedrugs, ill health, or undernutrition? Scand J Gastroenterol 1983;18:57-60.

23 Karbach U, Ewe K, Schramm P. Quality of semen in patients with Crohn's disease. Z Gastroenterol 1982;20:314-20.

24 El-Tawil AM. Zinc deficiency in men with Crohn's disease may contribute to poor sperm function and male infertility. Andrologia 2003;35:337-41.

25 Ludvigsson JF, Ludvigsson J. Inflammatory bowel disease in mother or father and neonatal outcome. Acta Paediatr 2002;91:145-51.

26 Fonager K, Sorensen HT, Olsen J, et al. Pregnancy outcome for women with Crohn's disease: a follow-up study based on linkage between national registries. Am J Gastroenterol 1998;93:2426-30.

27 Kornfeld D, Cnattingius S, Ekbom A. Pregnancy outcomes in women with inflammatory bowel disease-a population-based cohort study. Am J Obstet Gynecol 1997; 177:942-6.

28 Norgard B, Fonager K, Sorensen HT, et al. Birth outcomes of women with ulcerative colitis: a nationwide Danish cohort study. Am J Gastroenterol 2000;95:3165-70.

29 Dominitz JA, Young JC, Boyko EJ. Outcomes of infants born to mothers with inflammatory bowel disease: a population-based cohort study. Am J Gastroenterol 2002;97:641-8. 
30 Norgard B, Puho E, Pedersen L, et al. Risk of congenital abnormalities in children born to women with ulcerative colitis: a population-based, casecontrol study. Am J Gastroenterol 2003;98:2006-10.

31 Mahadevan USW, Sandborn W, Hakimian S. Pregnancy outcomes in women with inflammatory bowel disease: a population based cohort study. Gastroenterol 2005;128(suppl 2):A322-3.

32 Morales M, Berney T, Jenny A, et al. Crohn's disease as a risk factor for the outcome of pregnancy. Hepatogastroenterology 2000;47:1595-8.

33 Nielsen $\mathrm{OH}$, Andreasson B, Bondesen $\mathrm{S}$, et al. Pregnancy in ulcerative colitis. Scand J Gastroenterol 1983;18:735-42.

34 Bush MC, Patel S, Lapinski RH, et al. Perinatal outcomes in inflammatory bowel disease. J Matern Fetal Neonatal Med 2004;15:237-41

35 Fedorkow DM, Persaud D, Nimrod CA. Inflammatory bowel disease: a controlled study of late pregnancy outcome. Am J Obstet Gynecol 1989; 160:998-1001

36 Moser MA, Okun NB, Mayes DC, et al. Crohn's disease, pregnancy, and birth weight. Am J Gastroenterol 2000;95:1021-6.

37 Nielsen OH, Andreasson B, Bondesen S, et al. Pregnancy in Crohn's disease. Scand J Gastroenterol 1984;19:724-32.

38 Ilnyckyii A, Blanchard JF, Rawsthorne P, et al. Perianal Crohn's disease and pregnancy: role of the mode of delivery. Am J Gastroenterol 1999;94:3274-8.

39 Brandt L, Estabrook SG, Reinus JF. Results of a survey to evaluate whether vaginal delivery and episiotomy lead to perineal involvement in women with Crohn's disease. Am J Gastroenterol 1995;90:1918-22.

40 Hahnloser D, Pemberton JH, Wolff BG, et al. Pregnancy and delivery before and after ileal pouch-anal anastomosis for inflammatory bowel disease: immediate and long-term consequences and outcomes. Dis Colon Rectum 2004; 47:1127-35

41 Craxi A, Pagliarello F. Possible embryotoxicity of sulfasalazine. Arch Intern Med 1980;140:1674.

42 Hoo JJ, Hadro TA, Von Behren P. Possible teratogenicity of sulfasalazine. N Engl J Med 1988;318:1128.

43 Newman NM, Correy JF. Possible teratogenicity of sulphasalazine. Med J Aust 1983;1:528-9.

44 Mogadam M, Dobbins WO iii, Korelitz Bl, et al. Pregnancy in inflammatory bowel disease: effect of sulfasalazine and corticosteroids on fetal outcome. Gastroenterology 1981;80:72-6.

45 Norgard B, Czeizel AE, Rockenbauer M, et al. Population-based case control study of the safety of sulfasalazine use during pregnancy. Aliment Pharmacol Ther 2001;15:483-6.

46 Esbjorner E, Jarnerot G, Wranne L. Sulphasalazine and sulphapyridine serum levels in children to mothers treated with sulphasalazine during pregnancy and lactation. Acta Paediatr Scand 1987;76:137-42.

47 Habal FM, Hui G, Greenberg GR. Oral 5-aminosalicylic acid for inflammatory bowel disease in pregnancy: safety and clinical course. Gastroenterology 1993;105:1057-60.

48 Marteau P, Tennenbaum R, Elefant E, et al. Foetal outcome in women with inflammatory bowel disease treated during pregnancy with oral mesalazine microgranules. Aliment Pharmacol Ther 1998;12:1101-8.

49 Trallori G, d'Albasio G, Bardazzi G, et al. 5-Aminosalicylic acid in pregnancy: clinical report. Ital J Gastroenterol 1994;26:75-8.

50 Diav-Citrin O, Park YH, Veerasuntharam G, et al. The safety of mesalamine in human pregnancy: a prospective controlled cohort study. Gastroenterology 1998;114:23-8.

51 Norgard B, Fonager K, Pedersen L, et al. Birth outcome in women exposed to 5-aminosalicylic acid during pregnancy: a Danish cohort study. Gut 2003;52:243-7.

52 Nelis GF. Diarrhoea due to 5-aminosalicylic acid in breast milk. Lancet 1989;1:383.

53 Burtin P, Taddio A, Ariburnu O, et al. Safety of metronidazole in pregnancy a meta-analysis. Am J Obstet Gynecol 1995;172:525-9.

54 Caro-Paton T, Carvajal A, Martin de Diego I, et al. Is metronidazole teratogenic? A meta-analysis. Br J Clin Pharmacol 1997;44:179-82.

55 Piper JM, Mitchel EF, Ray WA. Prenatal use of metronidazole and birth defects: no association. Obstet Gynecol 1993;82:348-52.

56 Sorensen HT, Larsen $\mathrm{H}$, Jensen ES, et al. Safety of metronidazole during pregnancy: a cohort study of risk of congenital abnormalities, preterm delivery and low birth weight in 124 women. J Antimicrob Chemothe 1999:44:854-6.

57 Diav-Citrin O, Shechtman S, Gotteiner T, et al. Pregnancy outcome after gestational exposure to metronidazole: a prospective controlled cohort study. Teratology 2001;63:186-92.

58 Czeizel AE, Rockenbaver M. A population based case-control teratologic study of oral metronidazole treatment during pregnancy. Br J Obstet Gynaecol 1998;105:322-7.

59 Niebyl JR. Antibiotics and other anti-infective agents in pregnancy and lactation. Am J Perinatol 2003;20:405-14.

60 Loebstein R, Addis A, Ho E, et al. Pregnancy outcome following gestationa exposure to fluoroquinolones: a multicenter prospective controlled study. Antimicrob Agents Chemother 1998;42:1336-9.

61 Larsen H, Nielsen GL, Schonheyder HC, et al. Birth outcome following maternal use of fluoroquinolones. Int J Antimicrob Agents 2001;18:259-62.

62 Briggs GG, Freeman FR, Yaffe SJ. Drugs in pregnancy and lactation, 7th edn., Philadelphia, PA: Lippincott, Williams, and Wilkins 2005.

63 Bertoli D, Borelli G. Fertility study of rifaximin (L/105) in rats. Chemioterapia 1986:5:204-7.

64 Xifaxan (package insert). Morrisville, NC: Salix Pharmaceuticals, 2005

65 Czeizel AE, Rockenbauer M, Sorensen HT, et al. Augmentin treatment during pregnancy and the prevalence of congenital abnormalities: a population- based case-control teratologic study. Eur J Obstet Gynecol Reprod Biol 2001;97:188-92.

66 Berkovitch M, Diav-Citrin O, Greenberg R, et al. First-trimester exposure to amoxycillin/clavulanic acid: a prospective, controlled study. $\mathrm{Br} J$ Clin Pharmacol 2004:58:298-302.

67 Rodriguez-Pinilla E, Martinez-Frias ML. Corticosteroids during pregnancy and oral clefts: a case-control study. Teratology 1998;58:2-5.

68 Carmichael SL, Shaw GM. Maternal corticosteroid use and risk of selected congenital anomalies. Am J Med Genet 1999;86:242-4.

69 Gur C, Diav-Citrin O, Shechtman S, et al. Pregnancy outcome after first trimester exposure to corticosteroids: a prospective controlled study. Reprod Toxicol 2004; 18:93-101.

70 Park-Wyllie L, Mazzotta P, Pastuszak A, et al. Birth defects after maternal exposure to corticosteroids: prospective cohort study and meta-analysis of epidemiological studies. Teratology 2000;62:385-92.

71 Armenti VT, Moritz MJ, Cardonick EH, et al. Immunosuppression in pregnancy: choices for infant and maternal health. Drugs 2002;62:2361-75.

72 Gluck PA, Gluck JC. A review of pregnancy outcomes after exposure to orally inhaled or intranasal budesonide. Curr Med Res Opin 2005;21:1075-84.

73 Norjavaara E, de Verdier MG. Normal pregnancy outcomes in a population-based study including 2,968 pregnant women exposed to budesonide. J Allergy Clin Immunol 2003;111:736-42.

74 Patlas N, Golomb G, Yaffe P, et al. Transplacental effects of bisphosphonates on fetal skeletal ossification and mineralization in rats. Teratology 1999;60:68-73

75 Del Campo M, Kosaki K, Bennett FC, et al. Developmental delay in fetal aminopterin/methotrexate syndrome. Teratology 1999;60:10-12.

76 Polifka JE, Friedman JM. Teratogen update: azathioprine and 6mercaptopurine. Teratology 2002;65:240-61.

77 Saarikoski S, Seppala M. Immunosuppression during pregnancy: transmission of azathioprine and its metabolites from the mother to the fetus. Am J Obstet Gynecol 1973:115:1100-6.

78 Hou S. Pregnancy in renal transplant recipients. Adv Ren Repl Ther 2003;10:40-7

79 Norgard B, Pedersen L, Fonager K, et al. Azathioprine, mercaptopurine and birth outcome: a population-based cohort study. Aliment Pharmacol Ther 2003; 17:827-34

80 Alstead EM, Ritchie JK, Lennard-Jones JE, et al. Safety of azathioprine in pregnancy in inflammatory bowel disease. Gastroenterology 1990:99:443-6.

81 Francella A, Dyan A, Bodian C, et al. The safety of 6-mercaptopurine for childbearing patients with inflammatory bowel disease: a retrospective cohort study. Gastroenterology 2003;124:9-17.

82 Khan ZH, Mayberry JF, Spiers N et al. Retrospective case series analysis of patients with inflammatory bowel disease on azathioprine. A district general hospital experience. Digestion 2000;62:249-54.

83 Moskovitz DN, Bodian C, Chapman ML, et al. The effect on the fetus of medications used to treat pregnant inflammatory bowel-disease patients. Am J Gastroenterol 2004;99:656-61.

84 Bar Oz B, Hackman R, Einarson T, et al. Pregnancy outcome after cyclosporine therapy during pregnancy: a meta-analysis. Transplantation 2001;71:1051-5.

85 Bertschinger P, Himmelmann A, Risti B, et al. Cyclosporine treatment of severe ulcerative colitis during pregnancy. Am J Gastroenterol 1995;90:330

86 Anderson JB, Turner GM, Williamson RC. Fulminant ulcerative colitis in late pregnancy and the puerperium. J R Soc Med 1987;80:492-4.

87 Jain A, Venkataramanan R, Fung JJ, et al. Pregnancy after liver transplantation under tacrolimus. Transplantation 1997;64:559-65.

88 Kainz A, Harabacz I, Cowlrick IS, et al. Analysis of 100 pregnancy outcomes in women treated systemically with tacrolimus. Transpl Int 2000;13/suppl 1):S299-300

89 Armenti VT, Moritz MJ, Davison JM. Drug safety issues in pregnancy following transplantation and immunosuppression: effects and outcomes. Drug Saf 1998;19:219-32.

90 Baumgart DC, Sturm A, Wiedenmann B, et al. Uneventful pregnancy and neonatal outcome with tacrolimus in refractory ulcerative colitis. Gut 2005;54:1822-3.

91 Ehrenpreis ED, Kane SV, Cohen LB, et al. Thalidomide therapy for patients with refractory Crohn's disease: an open-label trial. Gastroenterology 1999; 117:1271-7

92 Celgene-Corporation. Thalomid. Product Information, 2000.

93 Lichtenstein G, Cohen RD, Feagan BG, et al. Safety of infliximab in Crohn's disease: data from the 5000-patient TREAT registry. Gastroenterology 2004; 126(suppl):A54.

94 Katz JA, Antoni C, Keenan GF, et al. Outcome of pregnancy in women receiving infliximab for the treatment of Crohn's disease and rheumatoid arthritis. Am J Gastroenterol 2004:99:2385-92.

95 Mahadevan U, Kane S, Sandborn WJ, et al. Intentional infliximab use during pregnancy for induction or maintenance of remission in Crohn's disease. Aliment Pharmacol Ther 2005;21:733-8.

96 Vasiliauskas E, Dubinsky M, Targan S. High serum levels of infliximab detected in the newborn of a mother receiving Infliximab during pregnancy. Gastroenterology 2005; (suppl 2):33.

97 Peltier M, James D, Ford J, et al. Infliximab levels in breast-milk of a nursing Crohn's patient. Am Coll Gastroenterol 2001;96(suppl 1):P258.

98 Hanauer SB, Lukas M, MAclntosh D, et al. A randomized, double-blind, placebo controlled trial of the human anti-TNF alpha monoclonal antibody 
adalimumab for the induction of remission in patients with moderate to severely active Crohn's disease. Gastroenterology 2004;127:332.

99 Vesga L, Terdiman JP, Mahadevan U. Adalimumab use in pregnancy. Gut 2005; 54:890.

100 Olsen SF, Sorensen JD, Secher NJ, et al. Randomised controlled trial of effect of fish-oil supplementation on pregnancy duration. Lancet 1992;339:1003-7.

101 Rossi E, Costa M. Fish oil derivatives as a prophylaxis of recurrent miscarriage associated with antiphospholipid antibodies (APL): a pilot study. Lupus 1993;2:319-23.

1206

102 Levi AJ, Fisher AM, Hughes L, et al. Male infertility due to sulphasalazine. Lancet 1979;2:276-8.

103 Toovey S, Hudson E, Hendry WF, et al. Sulphasalazine and male infertility: reversibility and possible mechanism. Gut 1981;22:445-51.

104 Birnie GG, McLeod TI, Watkinson G. Incidence of sulphasalazine-induced male infertility. Gut 1981;22:452-5.

105 Chatzinoff M, Guarino JM, Corson SL, et al. Sulfasalazine-induced abnormal sperm penetration assay reversed on changing to 5-aminosalicylic acid enemas. Dig Dis Sci 1988;33:108-10.

106 Kjaergaard N, Christensen LA, Lauritsen JG, et al. Effects of mesalazine substitution on salicylazosulfapyridine-induced seminal abnormalities in men with ulcerative colitis. Scand J Gastroenterol 1989;24:891-6.

107 Moody GA, Probert C, Jayanthi V, et al. The effects of chronic ill health and treatment with sulphasalazine on fertility amongst men and women with inflammatory bowel disease in Leicestershire. Int J Colorectal Dis inflammatory bow

108 Naz RK. Modalities for treatment of antisperm antibody mediated infertility: novel perspectives. Am J Reprod Immunol 2004;51:390-7.

109 French AE, Koren G. Effect of methotrexate on male fertility. Can Fam Physician 2003;49:577-8.

110 Dejaco C, Mittermaier C, Reinisch W. Azathioprine treatment and male fertility in inflammatory bowel disease. Gastroenterology 2001;121:1048-53
111 Sills ES, Tucker MJ. First experience with intracytoplasmic sperm injection for extreme oligozoospermia associated with Crohn's disease and 6mercaptopurine chemotherapy. Asian J Androl 2003;5:76-8.

112 Oakberg EF, Crosthwait CD, Raymer GD. Spermatogenic stage sensitivity to 6-mercaptopurine in the mouse. Mutat Res 1982;94:165-78.

113 Ligumsky M, Badaan S, Lewis $\mathrm{H}$, et al. Effects of 6-mercaptopurine treatmen on sperm production and reproductive performance: a study in male mice. Scand J Gastroenterol 2005:40:444-9.

114 Rajapakse RO, Korelitz BI, Zlatanic J, et al. Outcome of pregnancies when fathers are treated with 6-mercaptopurine for inflammatory bowel disease. Am J Gastroenterol 2000;95:684-8.

115 Ben-Neriah Z, Ackerman Z. WAGR syndrome in a baby-the result of 6-MP treatment in a father affected by Crohn's disease? Am J Gastroenterol $2001 ; 96: 251$.

116 Norgard B, Pedersen L, Jacobsen J, et al. The risk of congenital abnormalities in children fathered by men treated with azathioprine or mercaptopurine before conception. Aliment Pharmacol Ther 2004; 19:679-85

117 Treacy G. Using an analogous monoclonal antibody to evaluate the reproductive and chronic toxicity potential for a humanized anti-TNFalpha monoclonal antibody. Hum Exp Toxicol 2000;19:226-8.

118 Mahadevan U, Terdiman JP, Aron J, et al. Infliximab and semen quality in men with inflammatory bowel disease. Inflamm Bowel Dis 2005:11:395-9.

119 Pentikainen V, Erkkila K, Suomalainen L, et al. TNFalpha down-regulates the Fas ligand and inhibits germ cell apoptosis in the human testis. J Clin Endocrinol Metab 2001;86:4480-8.

120 Suominen JS, Wang Y, Kaipia A, et al. Tumor necrosis factor-alpha (TNFalpha) promotes cell survival during spermatogenesis, and this effect can be blocked by infliximab, a TNF-alpha antagonist. Eur J Endocrinol 2004;151:629-40.

121 Administration FDA. Regulations 1980;44:37434-67. 